\title{
A Pilot Study on Hepatitis E Virus (HEV) Epidemiology in Animal Reservoirs in Bulgaria
}

\section{Andrea Palombieri}

Universita degli Studi di Teramo Facolta di Medicina Veterinaria

\section{Ilia Tsachev}

Trakia University Stara Zagora: Trakijski Universitet Stara Zagora

\section{Vittorio Sarchese}

Universita degli Studi di Teramo Facolta di Medicina Veterinaria

\section{Paola Fruci}

Universita degli Studi di Teramo Facolta di Medicina Veterinaria

\section{Federica Di Profio}

Universita degli Studi di Teramo Facolta di Medicina Veterinaria

Roman Pepovich

Sofia University

\section{Magdalena Baymakova}

Military Medical Academy

\section{Fulvio Marsilio}

Universita degli Studi di Teramo Facolta di Medicina Veterinaria

\section{Vito Martella}

Università degli Studi di Bari Aldo Moro Facoltà di medicina veterinaria: Universita degli Studi di Bari Aldo Moro Dipartimento di Medicina Veterinaria

\section{Barbara Di Martino ( $\nabla$ bdimartino@unite.it)}

University of Teramo https://orcid.org/0000-0001-6192-7166

\section{Research Article}

Keywords: hepatitis E virus (HEV), epidemiology, animal reservoirs, Bulgaria, A pilot study, Gt3 subtype c

Posted Date: August 3rd, 2021

DOI: https://doi.org/10.21203/rs.3.rs-751830/v1

License: (c) (i) This work is licensed under a Creative Commons Attribution 4.0 International License. Read Full License 


\section{Abstract}

Information on hepatitis E virus (HEV) epidemiology in animal reservoirs in Bulgaria is still lacking. Herein, by screening HEV seropositive sera obtained from Bulgarian swine and wild boars, viral RNA was detected at high prevalence rate (28.2\%) in industrial pigs. Sequence analysis of the partial polymerase (RdRp) region revealed the highest genetic correlation with HEVs of genotype (Gt) 3 identified in French and Dutch patients. For three such strains a 700-bp fragment of the ORF 2 gene was generated. On phylogenetic analysis, the Bulgarian strains clustered tightly $(93.8-98.3 \% \mathrm{nt})$ with human and animal HEVs classified within the Gt3 subtype $c$.

\section{Main Text}

Hepatitis E virus (HEV) is the main cause of acute viral hepatitis worldwide. Although, HEV causes mostly self-limiting hepatitis, infection in immunosuppressed patients such as organ transplant recipients can progress into chronicity [1]. The possible association has been made between HEV infection and a wide range of extrahepatic manifestations including neurological and renal injuries [2].

HEV, classified in the family Hepeviridae, is a single-stranded, positive-sense RNA virus of $\sim 7.2 \mathrm{~kb}$ in size that in the infected host exists in two distinct forms, as non-enveloped (neHEV) particle of approximately 27-34 $\mathrm{nm}$ in diameter [3] when secreted in the faeces, or as quasi-enveloped (eHEV) virion in circulating blood and in the supernatant of infected cell cultures [4]. HEVs of mammalian origin are classified along with avian strains into the genus Orthohepevirus, comprising four species, Orthohepevirus $A-D$ [5]. The species Orthohepevirus $A$ includes at least eight distinct genotypes (Gts), with four major Gts (1-4) implicated in human disease. Gt1 and Gt2 infections are restricted to humans and cause large epidemics in developing countries due to poor sanitation and lack of clean drinking water, while Gt3 and Gt4 are zoonotic and cause sporadic and cluster cases of hepatitis $E$ in both industrialised and developing countries [6]. In the last few years, a steady increase in cases of human HEV infection has been observed in Europe, mostly of autochthonous origin [7]. In Bulgaria, the burden of disease and transmission pathways for hepatitis E cases have not been sufficiently defined yet. However, accumulated data suggest that HEV infection could represent a public health problem in local population. A recent serosurvey conducted on Bulgarian blood donors reported an overall HEV IgG prevalence of $25.9 \%$ (144/555), with Regional differences ranging from $21.3 \%$ to $28.8 \%$ [8]. Furthermore, a critical analysis from 23 independent Bulgarian studies, that combined HEV IgG, IgM and RNA markers from 2,257 hospitalised patients with clinical presentation of acute liver injuries, estimated that in the time frame 1995 - 2018 the overall HEV infection prevalence was 13.1\% [9]. HEV RNA was found in 90 (87.3\%) out 103 sera collected between January 2013 and May 2015 from patients with diagnosed hepatitis E. Upon sequence analysis of a sub-set (64/90) of positive sera, Gt3 HEV RNA was identified in $98.4 \%(63 / 64)$ of the assessed samples [10].

Furthermore, serological surveys have revealed high prevalence rates either in swine or wild boars [11-15], suggesting a high viral circulation in local animal populations assessed. However, information on HEV 
molecular epidemiology and on the genetic features of the circulating strains has not yet been collected, thus hindering to depict a complete portrait on the impact that animal reservoirs may play in the transmission of infection to humans. In this study, we report the results of a preliminary molecular survey performed on serum samples collected between January 2018 and February 2020 from a selection of 39 HEV seropositive pigs and wild boars in different districts of Bulgaria [12, 14, 15]. In detail, ten sera (collection SNB: Swine Northern Bulgaria) were obtained from fattening pigs bred in an industrial farrowto-finish farm in Vidin district (Northern Bulgaria), ten (collection SSB: Swine Southern Bulgaria) were from fattening pigs farmed in an industrial Southern Bulgaria herd located in the Yambol district, and an additional nine group of sera (collection SEB: Swine Eastern Bulgaria) was collected from fattening East Balkan swine, an aboriginal pig breed, from Burgas district (Eastern Bulgaria). Furthermore, 10 sera were collected from wild boars during the official hunting season (from November 2019 to February 2020) in Western district (Blagoevgrad) of Bulgaria. Information about gender and age were not available. Total RNA was extracted from $200 \mu$ of each serum by using the ExgeneTM Viral DNA/RNA mini (TEMA Ricerca, Bologna, Italy), following the manufacturer's instructions and stored at $-80^{\circ} \mathrm{C}$ until use. The presence of Orthohepevirus $A$ RNA was assessed by real-time reverse transcription PCR (qRT-PCR), targeting a conserved 68 nucleotide region of ORF3 gene, as previously described [16]. An HEV plasmid was constructed by cloning the 68 bp ORF3 fragment of a wild boar strain (HEV/WB/P6-15/ITA, accession no. KU508285) [17] into the Topo TA cloning vector (Invitrogen, Ltd, Milan, Italy). Tenfold serial dilutions of the plasmid ranging from $10^{0}$ to $10^{9}$ copies per reaction were used in each PCR run. A standard curve was generated from the copy number and corresponding cycle threshold (Ct) value. The first WHO international standard for HEV RNA (code 6329/10) was used to standardize the system. Molecular screening for other members of the genus Orthohepevirus was carried out by a pan-hepevirus heminested RT-PCR using broadly reactive primers designed to amplify all members of the family Hepeviridae [18] and targeting a region of 338-bp of the viral RNA-dependent RNA polymerase (RdRp) complex. All of the positive amplicons were excised from the gel and purified using the QIAquick gel extraction kit (Qiagen $\mathrm{GmbH}$, Hilden, Germany). Each fragment was then subjected to direct sequencing using BigDye Terminator Cycle chemistry and 3730 DNA Analyzer (Applied Biosystems, Foster, CA). Basic Local Alignment Search Tool (BLAST; http://www.ncbi.nlm.nih.gov) and FASTA

(http://www.ebi.ac.uk/fasta33) with default values were used to find homologous hits. The alignment of the sequences was conducted using the MAFFT multiple alignment program version 7.388 plugin of the Geneious Prime software V. 21.1.1 (Biomatters Ltd., Auckland, New Zealand).

On molecular screening by qRT-PCR of 39 serum samples, HEV RNA was detected in a total of 11 sera $(28.2 \%$; $11 / 39)$ with viral loads ranging from $7.4 \times 100$ to $3.5 \times 102$ RNA copies/5 $\mu$ l of template (mean $1.3 \times 102$ RNA copies) (Table 1). Out of 11 positive specimens, $10(90.9 \% ; 10 / 11)$ were identified in pigs from Northern Bulgaria (collection SNB) with an overall prevalence of $100 \%(10 / 10)$ and only one $(10.0 \%$; $1 / 10$ ) was detected in a pig from the collection SSB. None of the sera from East Balkan swine and from wild boars resulted positive for HEV RNA. When testing the sera with pan-hepeviruses primer pairs [18], nine samples all of collection SNB $(90.0 \% ; 9 / 10)$, yielded a band of expected size (Table 1). Partial RdRp sequences were determined and deposited in GenBank under the accession numbers MZ519907- 
MZ519915. Upon BLAST (www.ncbi.nlm.nih.gov/blast) and FASTA (www.ebi.ac.uk/fasta33) analyses, the amplicons shared $99.4-100 \%$ nucleotide (nt) identity to each other and displayed the closest relatedness (96.4-98.8\%) to human HEV Gt3 strains previously detected in serum samples from French patients (GenBank accession no. MW355218, MW355367, MW355268, MW355295) [19] and in solid organ transplant recipients in the Netherlands (GenBank accession no. JQ015416 and JQ015424) [20].

In order to achieve a more clear characterization of swine HEVs detected, all of the positive samples were further tested by RT-PCR and nested PCR targeting respectively regions of $755 \mathrm{bp}$ and $348 \mathrm{bp}$ of the ORF2 gene [21]. The sequence of $~ 700 \mathrm{nt}$ was obtained for the strains SNB2, SNB6 and SNB8 (GenBank accession no. MZ555941-42 and MZ555944), whilst one additional specimen, HEV SNB7 (MZ555943), resulted positive after second-round amplification in nested PCR (Table 1). The partial ORF2 genes ( 700 nt) were compared to reference and prototype sequences of known HEV Gt3 subtypes [22] and used to generate a Maximum Likelihood tree [23]. In the partial capsid-based tree (Fig. 1), the Bulgarian strains segregated within the clade 1 (abchkijlm) $[22,24,25]$ displaying the highest identity $(93.8-98.3 \%)$ to animal and human HEVs assigned to subtype c. Identities to the other Gt3 subtypes were from $81.6 \%$ (Gt3ra) to $88.9 \%$ (Gt3i).

We next compared the ORF2 sequences of the porcine strains detected in this study with the sequences of 63 Bulgarian human Gt3 HEVs [10] available on the database, since the sequences overlapped by a 240 nt portion. The overall nucleotide identity ranged from $80.1 \%$ to $93.9 \%$, with the best match (92.093.9\%) to the strains ISS2/Sof2013 and ISS76/Dob/2014 (GenBank accession no. MH203165 and MH203204) classified as subtype c (Table 2).

In the last few years, improved surveillance activities in Bulgaria have shown that zoonotic HEV infection is emerging [8-10]. Herein, to provide insights into the epidemiology of HEV, we screened by a multitarget gene approach a collection of sera from Bulgarian swine and wild boars previously found positive for HEV IgG antibodies. HEV RNA was detected in $28.2 \%$ (11/39) of the animals tested. This high molecular rate seems to confirm previous suspicious on a lively viral spread in the geographical area analysed. Serosurveys performed in Bulgaria report prevalences ranging from $40.0 \%$ to $60.3 \%$ in domestic swine [11-13], to $40.8 \%$ in wild boars [15] and to $82.5 \%$ in East Balkan swine (autochthonous pig breed) [14].

Out of the four collections assessed in this study, the highest prevalence $(100 \% ; 10 / 10)$ was found in pig sera obtained from a closed-cycle industrial farm in North Bulgaria (collection SNB), in which specific HEV antibodies were detected with an overall rate of $63.3 \%$ (19/30) (data unpublished). Accordingly, it could be hypothesized that at the sampling time point most of the pigs were seropositive and viremic. Also, sequence analysis of the RdRp fragment (338 nt) generated for 9 strains revealed a clonal origin (99.4-100\% identity) that may be compatible with the circulation of the same variant within the herd investigated.

Only one strain (10.0\%) from collection SSB with an estimated seroprevalence of $23.3 \%$ [12], resulted positive by quantitative RT-PCR, but attempts made to obtain sequence data failed. All serum samples collected from East Balkan swine (seroprevalence rate of 76.7\%) [14] and wild boars (seroprevalence rate 
of 73.3\%) [15] resulted negative either when tested with quantitative or conventional PCR. It is likely that these results rather than mirroring the actual geographical distribution of HEV in Bulgaria, are merely linked to other factors such as the absence of viraemic status at the time of sampling and/or the limited number of animals analysed.

Data on the diffusion and distribution of HEV Gt3 subtypes circulating in Bulgaria in human population are still limited. Phylogenetic and coalescence analyses based on a 355-nt partial ORF2 region of 63 HEV Gt3 strains identified in patients with hepatitis $E[10,26]$ provided evidence that subtypes $3 e(39 / 63,62 \%)$, $3 f(15 / 63,24 \%)$ and $3 c(8 / 63,13 \%)$ are the most common. In our study, sequence analysis of a 700 -nt portion of ORF2 allowed a subtyping classification of the swine Bulgarian strains SNB2, SNB6 and SNB8, revealing the highest genetic correlation to HEV Gt3 subtype c. This cluster comprises HEV strains of human and animal origin frequently signalled in Europe [25]. Accordingly, the spread of this subtype in Bulgaria could be accounted for by geographical changes in the circulation of HEV strains, likely due to trading of HEV-infected animals from other European countries. We retrieved from GenBank database all of the Bulgarian HEV human sequences [10] and compared with the porcine sequences generated in this study. On pairwise alignment of a 240-nt ORF2 overlapping fragment, two human sequences (ISS2/Sof2013 and ISS76/Dob/2014) were genetically similar (92.0-93.9\%) to the HEV strains detected in swine, suggesting that similar HEVs are circulating in humans and animals in the same geographical setting.

In summary, our study confirmed molecularly the presence of HEV in pigs in Bulgaria. A high prevalence of HEV RNA was found in an industrial pig farm from Northern Bulgaria. Large-scale molecular surveillance at environmental/animal/food levels could be useful to improve the knowledge on HEV ecology in order to establish local adequate control measures.

\section{Declarations}

\section{Acknowledgements}

The present study has been carried out in the framework of the Project "Demetra" (Dipartimenti di Eccellenza 2018 - 2022, CUP_C46C18000530001), funded by the Italian Ministry for Education, University and Research.

\section{Conflict of interest}

All Authors declare that there are no financial or other relationships that might lead to a conflict of interest. All authors have seen and approved the manuscript and have contributed significantly to the work.

\section{Ethics standard}

This study was approved by the Ethics Committee in Animal Experimentation and Animal Welfare at Trakia University, Stara Zagora (Bulgaria), and was conducted according to the ethical principles of 
animal experimentation, adopted by the Bulgarian Ministry of Agriculture, Food and Forestry.

\section{Availability of data and material}

The data that support the findings of this study are openly available in the GenBank database at https://www.ncbi.nlm.nih.gov/nucleotide/ under accession numbers MZ519907 - MZ519915 for RdRp region and MZ555941-MZ555944 for the partial ORF2 gene.

\section{References}

1. Kamar N, Selves J, Mansuy JM, Ouezzani L, Péron JM, Guitard J, Cointault O, Esposito L, Abravanel F, Danjoux M, Durand D, Vinel JP, Izopet J, Rostaing L (2008) Hepatitis E virus and chronic hepatitis in organ-transplant recipients. N Engl J Med 358(8):811-7. doi: 10.1056/NEJMoa0706992.

2. Pischke S, Hartl J, Pas SD, Lohse AW, Jacobs BC, Van der Eijk AA (2017) Hepatitis E virus: Infection beyond the liver? J Hepatol 66(5):1082-1095. doi: 10.1016/j.jhep.2016.11.016.

3. Nagashima S, Takahashi M, Kobayashi T, Tanggis, Nishizawa T, Nishiyama T, Primadharsini PP, Okamoto H (2017) Characterization of the Quasi-Enveloped Hepatitis E Virus Particles Released by the Cellular Exosomal Pathway. J Virol 91(22):e00822-17. doi: 10.1128/JVI.00822-17.

4. Takahashi M, Yamada K, Hoshino Y, Takahashi H, Ichiyama K, Tanaka T, Okamoto H (2008) Monoclonal antibodies raised against the ORF3 protein of hepatitis E virus (HEV) can capture HEV particles in culture supernatant and serum but not those in feces. Arch Virol 153(9):1703-13. doi: 10.1007/s00705-008-0179-6.

5. Purdy MA, Harrison TJ, Jameel S, Meng XJ, Okamoto H, Van der Poel WHM, Smith DB, Ictv Report Consortium (2017) ICTV Virus Taxonomy Profile: Hepeviridae. J Gen Virol 98(11):2645-2646. doi: 10.1099/jgv.0.000940.

6. Wang B, Meng XJ (2021) Hepatitis E virus: host tropism and zoonotic infection. Curr Opin Microbiol 59:8-15. doi: 10.1016/j.mib.2020.07.004.

7. Sooryanarain H, Meng XJ (2019) Hepatitis E virus: reasons for emergence in humans. Curr Opin Virol 34:10-17. doi: 10.1016/j.coviro.2018.11.006.

8. Baymakova M, Terzieva K, Popov R, Grancharova E, Kundurzhiev T, Pepovich R, Tsachev I (2021) Seroprevalence of Hepatitis E Virus Infection among Blood Donors in Bulgaria. Viruses 13(3):492. doi: 10.3390/v13030492.

9. Baymakova M, Popov GT, Pepovich R, Tsachev I (2019) Hepatitis E Virus Infection in Bulgaria: A Brief Analysis of the Situation in the Country. Open Access Maced J Med Sci 7(3):458-460. doi: 10.3889/oamjms.2019.073.

10. Bruni R, Villano U, Equestre M, Chionne P, Madonna E, Trandeva-Bankova D, Peleva-Pishmisheva M, Tenev T, Cella E, Ciccozzi M, Pisani G, Golkocheva-Markova E, Ciccaglione AR (2018) Hepatitis E virus genotypes and subgenotypes causing acute hepatitis, Bulgaria, 2013-2015. PLoS One 13(6):e0198045. doi: 10.1371/journal.pone.0198045. 
11. Pishmisheva M, Baymakova M, Golkocheva-Markova E, Kundurzhiev T, Pepovich R, Popov GT, Tsachev I (2018) First serological study of hepatitis E virus infection in pigs in Bulgaria. Comptes Rendus de l'Academie Bulg des Sci 71(7),1001-1008. https://doi.org/10.7546/CRABS.2018.07.18

12. Tsachev I, Baymakova M, Ciccozzi M, Pepovich R, Kundurzhiev T, Marutsov P, Dimitrov KK, Gospodinova K, Pishmisheva M, Pekova L (2019) Seroprevalence of Hepatitis E Virus Infection in Pigs from Southern Bulgaria. Vector Borne Zoonotic Dis 19(10):767-772. doi: 10.1089/vbz.2018.2430.

13. Takova K, Koynarski T, Minkov I, Ivanova Z, Toneva V, Zahmanova G (2020) Increasing Hepatitis E Virus Seroprevalence in Domestic Pigs and Wild Boar in Bulgaria. Animals (Basel) 10(9):1521. doi: 10.3390/ani10091521.

14. Tsachev I, Baymakova M, Pepovich R, Palova N, Marutsov P, Gospodinova K, Kundurzhiev T, Ciccozzi M (2020) High Seroprevalence of Hepatitis E Virus Infection Among East Balkan Swine (Sus scrofa) in Bulgaria: Preliminary Results. Pathogens 9(11):911. doi: 10.3390/pathogens9110911.

15. Tsachev I, Baymakova M, Marutsov P, Gospodinova K, Kundurzhiev T, Petrov V, Pepovich R (2021) Seroprevalence of Hepatitis E Virus Infection Among Wild Boars in Western Bulgaria. Vector Borne Zoonotic Dis 21(6):441-445. doi: 10.1089/vbz.2020.2756.

16. Jothikumar N, Cromeans TL, Robertson BH, Meng XJ, Hill VR (2006) A broadly reactive one-step realtime RT-PCR assay for rapid and sensitive detection of hepatitis E virus. J Virol Methods 131(1):6571. doi: 10.1016/j.jviromet.2005.07.004.

17. Di Profio F, Melegari I, Sarchese V, Robetto S, Marruchella G, Bona MC, Orusa R, Martella V, Marsilio F, Di Martino B (2016) Detection and genetic characterization of hepatitis E virus (HEV) genotype 3 subtype $c$ in wild boars in Italy. Arch Virol 161(10):2829-34. doi: 10.1007/s00705-016-2964-y.

18. Drexler JF, Seelen A, Corman VM, Fumie Tateno A, Cottontail V, Melim Zerbinati R, Gloza-Rausch F, Klose SM, Adu-Sarkodie Y, Oppong SK, Kalko EK, Osterman A, Rasche A, Adam A, Müller MA, Ulrich RG, Leroy EM, Lukashev AN, Drosten C (2012) Bats worldwide carry hepatitis E virus-related viruses that form a putative novel genus within the family Hepeviridae. J Virol 86(17):9134-47. doi: 10.1128/JVI.00800-12.

19. Nicot F, Jeanne N, Roulet A, Lefebvre C, Carcenac R, Manno M, Dubois M, Kamar N, Lhomme S, Abravanel F, Izopet J (2018) Diversity of hepatitis E virus genotype 3. Rev Med Virol 28(5):e1987. doi: 10.1002/rmv.1987.

20. Pas SD, de Man RA, Mulders C, Balk AH, van Hal PT, Weimar W, Koopmans MP, Osterhaus AD, van der Eijk AA (2012) Hepatitis E virus infection among solid organ transplant recipients, the Netherlands. Emerg Infect Dis 18(5):869-72. doi: 10.3201/eid1805.111712.

21. Meng XJ, Purcell RH, Halbur PG, Lehman JR, Webb DM, Tsareva TS, Haynes JS, Thacker BJ, Emerson SU (1997) A novel virus in swine is closely related to the human hepatitis E virus. Proc Natl Acad Sci USA 94(18):9860-5. doi: 10.1073/pnas.94.18.9860.

22. Smith DB, Izopet J, Nicot F, Simmonds P, Jameel S, Meng XJ, Norder H, Okamoto H, van der Poel WHM, Reuter G, Purdy MA (2020) Update: proposed reference sequences for subtypes of hepatitis E 
virus (species Orthohepevirus A). J Gen Virol 101(7):692-698. doi: 10.1099/jgv.0.001435.

23. Kumar S, Stecher G, Li M, Knyaz C, Tamura K (2018) MEGA X: Molecular Evolutionary Genetics Analysis across Computing Platforms. Mol Biol Evol 35(6):1547-1549. doi:

10.1093/molbev/msy096.

24. Oliveira-Filho EF, König M, Thiel HJ (2013) Genetic variability of HEV isolates: inconsistencies of current classification. Vet Microbiol 165(1-2):148-54. doi: 10.1016/j.vetmic.2013.01.026.

25. Nicot F, Dimeglio C, Migueres M, Jeanne N, Latour J, Abravanel F, Ranger N, Harter A, Dubois M, Lameiras S, Baulande S, Chapuy-Regaud S, Kamar N, Lhomme S, Izopet J (2021) Classification of the Zoonotic Hepatitis E Virus Genotype 3 Into Distinct Subgenotypes. Front Microbiol 11:634430. doi: 10.3389/fmicb.2020.634430.

26. Cella E, Golkocheva-Markova E, Sagnelli C, Scolamacchia V, Bruni R, Villano U, Ciccaglione AR, Equestre M, Sagnelli E, Angeletti S, Ciccozzi M (2019) Human hepatitis E virus circulation in Bulgaria: Deep Bayesian phylogenetic analysis for viral spread control in the country. J Med Virol 91(1):132138. doi: $10.1002 / j m v .25296$.

\section{Tables}

Table 1

Molecular prevalence of HEV in sera collected form pigs and wild boars in Bulgaria.

\begin{tabular}{|c|c|c|c|c|c|}
\hline \multirow[t]{2}{*}{ Animal collections } & \multirow{2}{*}{$\begin{array}{l}\text { No. of animals } \\
\text { tested }\end{array}$} & \multicolumn{4}{|c|}{ Positive/Total (\%) } \\
\hline & & $\begin{array}{l}\text { qRT-PCR } \\
\text { ORF3 } \\
{[16]}\end{array}$ & $\begin{array}{l}\text { Emi-nested RT- } \\
\text { PCR } \\
\text { RdRp } \\
\text { [18] }\end{array}$ & $\begin{array}{l}\text { RT-PCR } \\
\text { ORF2 } \\
\text { [21] }\end{array}$ & $\begin{array}{l}\text { Nested } \\
\text { PCR } \\
\text { ORF2 } \\
{[21]}\end{array}$ \\
\hline $\begin{array}{l}\text { SNB (Swine Northern } \\
\text { Bulgaria) }\end{array}$ & 10 & $\begin{array}{l}10 / 10 \\
(100.0)\end{array}$ & $9 / 10(90.0)$ & $\begin{array}{l}3 / 10 \\
(30.0)\end{array}$ & $\begin{array}{l}4 / 10 \\
(40.0)\end{array}$ \\
\hline $\begin{array}{l}\text { SSB (Swine Southern } \\
\text { Bulgaria) }\end{array}$ & 10 & $\begin{array}{l}1 / 10 \\
(10.0)\end{array}$ & $0 / 10(0.0)$ & $\begin{array}{l}0 / 10 \\
(0.0)\end{array}$ & $\begin{array}{l}0 / 10 \\
(0.0)\end{array}$ \\
\hline $\begin{array}{l}\text { SEB (Swine Eastern } \\
\text { Bulgaria) }\end{array}$ & 9 & $0 / 9(0.0)$ & $0 / 9(0.0)$ & $\begin{array}{l}0 / 9 \\
(0.0)\end{array}$ & $0 / 9(0.0)$ \\
\hline Wild boars & 10 & $0 / 10(0.0)$ & $0 / 10(0.0)$ & $\begin{array}{l}0 / 10 \\
(0.0)\end{array}$ & $\begin{array}{l}0 / 10 \\
(0.0)\end{array}$ \\
\hline Total & 39 & $\begin{array}{l}11 / 39 \\
(28.2)\end{array}$ & 9/39 (23.1) & $\begin{array}{l}3 / 39 \\
(7.7)\end{array}$ & $\begin{array}{l}4 / 39 \\
(10.2)\end{array}$ \\
\hline
\end{tabular}


Table 2

Nucleotide (nt) sequence identity matrix (\%) based on the partial ORF2 gene of a selection of human HEV strains identified in Bulgaria [10]. The swine strains detected in this study are in bold.

\begin{tabular}{|c|c|c|c|c|c|}
\hline $\begin{array}{l}\text { HEV Gt3 } \\
\text { subtype }\end{array}$ & Strain name & $\begin{array}{l}\text { MZ555941 } \\
\text { SNB2 }\end{array}$ & $\begin{array}{l}\text { MZ555942 } \\
\text { SNB6 }\end{array}$ & $\begin{array}{l}\text { MZ555944 } \\
\text { SNB8 }\end{array}$ & $\begin{array}{l}\text { GenBank } \\
\text { Accession no. }\end{array}$ \\
\hline \multirow[t]{5}{*}{$3 c$} & ISS2/Sof2013 & $93.9 \%$ & $93.8 \%$ & $92.3 \%$ & MH203165 \\
\hline & ISS76/Dob2014 & $93.5 \%$ & $93.5 \%$ & $92.0 \%$ & MH203204 \\
\hline & ISS75/Plov2014 & $89.4 \%$ & $89.6 \%$ & $88.5 \%$ & MH203203 \\
\hline & ISS92/Sof2014 & $88.2 \%$ & $88.1 \%$ & $87.4 \%$ & MH203213 \\
\hline & ISS91/Paz2014 & $86.1 \%$ & $86.2 \%$ & $86.2 \%$ & $\mathrm{MH} 203212$ \\
\hline \multirow[t]{5}{*}{$3 e$} & ISS83/Paz2014 & $81.6 \%$ & $81.9 \%$ & $80.8 \%$ & MH203208 \\
\hline & ISS51/Paz2014 & $81.2 \%$ & $81.5 \%$ & $80.5 \%$ & MH203190 \\
\hline & ISS20/Plov2013 & $80.8 \%$ & $81.2 \%$ & $80.1 \%$ & MH203172 \\
\hline & ISS60/Plov2014 & $80.6 \%$ & $80.5 \%$ & $80.5 \%$ & MH203195 \\
\hline & ISS87/Sof2014 & $80.6 \%$ & $81.5 \%$ & $80.8 \%$ & MH203211 \\
\hline \multirow[t]{5}{*}{$3 f$} & ISS98/Paz2014 & $84.9 \%$ & $85.0 \%$ & $83.5 \%$ & MH203218 \\
\hline & ISS104/Bur2014 & $84.9 \%$ & $84.6 \%$ & $82.4 \%$ & MH203223 \\
\hline & ISS79/Sof2014 & $84.5 \%$ & $84.2 \%$ & $82.0 \%$ & MH203207 \\
\hline & ISS32/Jam2013 & $82.4 \%$ & $82.3 \%$ & $80.1 \%$ & MH203178 \\
\hline & ISS85/Paz2014 & $82.5 \%$ & $82.8 \%$ & $80.9 \%$ & $\mathrm{MH} 203210$ \\
\hline $3 i$ & ISS62/Paz2014 & $87.5 \%$ & $87.4 \%$ & $87.1 \%$ & MH203197 \\
\hline
\end{tabular}

Figures 


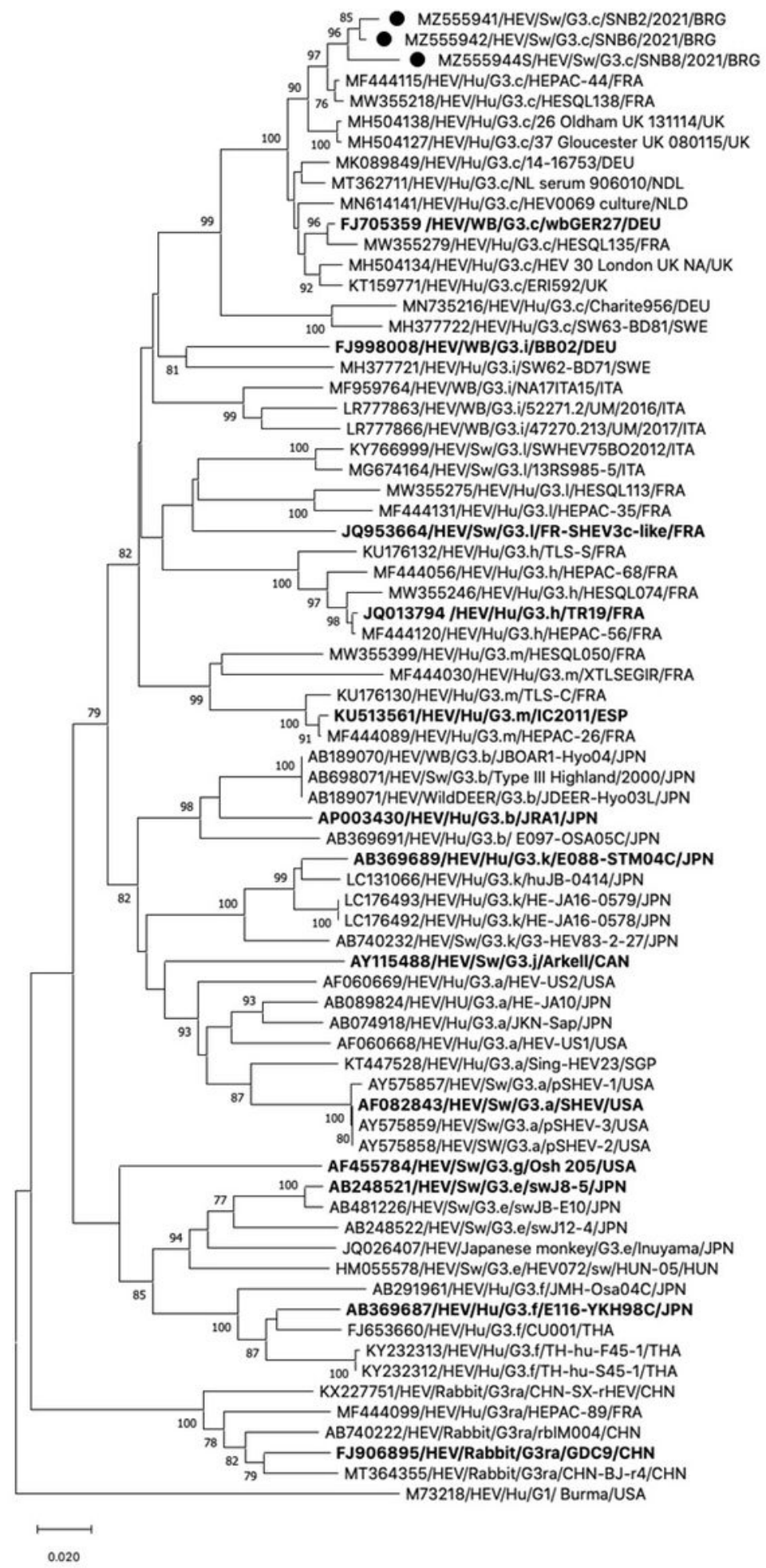

\section{Figure 1}

Phylogenetic tree constructed on the partial ORF2 gene of three Bulgarian HEV swine strains (GenBank accession no. MZ555941, MZ555942 and MZ555944). Tree was generated using Maximum Likelihood method based on the Tamura-Nei model and supplying statistical support with bootstrapping of 1000 replicates. The scale bar indicates nucleotide substitutions per site. The reference strains representative 
of each HEV Gt3 subtype are in boldface. The marker denotes the HEV sequences detected in this study. Evolutionary analyses were conducted in MEGA X [23].

\section{Supplementary Files}

This is a list of supplementary files associated with this preprint. Click to download.

- S1PalombierietalGenBankSubmission2479489.txt

- S2PalombierietalGenBankSubmission2481188.txt 